\title{
Drug Addiction and their Management: An Overview
}

\section{Anuradha Sharma* and Amar Chaudhary}

Faculty of Pharmaceutical Sciences, PCTE Group of Institutes, Baddowal, Ludhiana,

Punjab, India

*Corresponding Author: Anuradha Sharma, Associate Professor, Faculty of Phar-

maceutical Sciences, PCTE Group of Institutes, Baddowal, Ludhiana, Punjab, India.
Received: February 20, 2020;

Published: April 13, 2020

(C) All rights are reserved by Anuradha

Sharma and Amar Chaudhary .

\section{Abstract}

Drug addiction could be a term that means compulsive physiological want for use of a habit-forming substance, which is characterized by tolerance and well-defined physiological symptoms upon withdrawal. In this communication, the author has compiled all the drugs used for addiction, various tests for determination of addiction and their management.

Keywords: Addiction; Disorder; Drug; Management

\section{Introduction}

Addiction could be a term that means compulsive physiological want for use of a habit-forming substance (like opiate or nicotine) characterized by tolerance and well-defined physiological symptoms upon withdrawal [1].

Drug addiction, conjointly known as substance use disorder could be an illness that affects a human brain and behavior associate degreed ends up in an incapability to regulate the utilization of a legal or misappropriated drug or medication, e.g. substances like alcohol, marijuana and vasoconstrictive medicine [2]. Once persons are dependent, they will continue victimizing the drug despite the damage it causes. Drug addiction will begin with the experimental use of a narcotic in social things, and for a few individuals, the drug use becomes a lot of frequent. Significantly with opioids, habituation begins with exposure to prescribed medications, or receiving medications from a follower or relative UN agency has been prescribed the suppository [3].

The risk of addiction and the way quickly you become dependent varies by drugs. Some drugs, like opioid pain-killers have a better risk and cause addiction a lot more quickly than others. As their drug use will increase, they will realize that it's progressively tough to travel while not the drug. Makes an attempt to prevent drug use, it might cause intense cravings to feel physically unwell (withdrawal symptoms) [4].

\section{Impact on population}

It was found from literature survey the drugs impacted on the population in the following manner:
- The number of people aged 15 - 64 years: 11 - 21 million persons who have injected with drugs.

- The number of "problem drug users" aged 15 - 64 years: 16 38 million persons.

- A number of people who have used drugs at least once in the past year aged 15 - 64 years: 155 - 250 million persons.

- The total number of people aged 15-64 years in 2008: 4,396 million persons [5].

\section{Reasons}

Drug abuse is a disease that devastates millions of lives each year. People who trial with addiction cause pain not only for themselves but also for their beloved ones. There are enough causes of drug addiction. Every person has their own story, and each story is as heart affecting as the next. In this paper, we take a look at some of the leading reasons drug addiction occurs. Keep reading to learn how more and more people continue to fall into this trap.

\section{Loneliness}

Loneliness is a condition that is common to the human experience. Everyone feels lonely at different times in life for a variety of reasons. It can be painful, thus the desire to sensation the pain.

This is one of the most common stepping stones in the world of drugs and addiction. Loneliness is a pain that often feels unavoidable. It can be hard to verbalize what this pain feels like, and yet it's very certain and can cause the individual to be willing to do anything to make the irritation go away. Drugs generally help with the pain at first by satiating the brain. But this isn't a permanent so- 
lution and only leads to much larger pain and more difficult problems.

\section{Family history}

Another leading cause of addiction is family history and genetics. Other people raise up in homes where they are exposed to drugs and addiction. And options have it in their DNA because their mother or father abused drugs and passed the addiction down to their children genetically. Growing up in a house where drugs are current is generally too much for a child to deal with. And this display is generally the clue to a young person lowering into a life of addiction themselves.

\section{Pressure}

It's no secret that rival pressure is one of the very supreme forces in the world. This is especially true for the new generation. Everybody wanted to feel liked and to be traditional into certain associate groups, thus they are often willing to join in activities that aren't healthy. Pressure can be blamed for a huge percentage of addiction in teenagers. This is unfortunate but true.

\section{Escape from emotional pain}

There are many forms of emotional pain. Many people combat sadness, depression, violence, heartbreak, anxiety, fear, among other things and for many of these people, drugs represent an escape that will provide a reprieve for the emotional discomfort they experience on a daily basis [6].

\section{Prescription drugs}

Many people detect themselves addicted to drugs as a result of proper drugs recommended to them by their experts. This is typically because they've suffered damage or undergone a surgical method and need prescription drugs to help survivors with physical pain while they repair. This has absolutely become a bigger and bigger problem in recent years. People who take prescription drugs often begin to depend on the relief they provide and thus become addicted to the drug-related euphoria [7].

\section{Stress}

No one is immune to stress. We practice it in many forms, both in our personal and efficient lives. Stress can be devitalizing; thus, many populations turn to drugs and alcohol as a way to deal with the usual mental and physical stress of life.

\section{Trauma}

Trauma can be physical or psychological. Mental trauma can cause enormous anxiety and make a person sense out of control. For a sufferer of trauma, drugs symbolize an escape, a way to unfeeling the pain so that you don't have to assume about it anymore or contract with it in a healthier way.

\section{Pain from physical injury}

As discussed already, many doctors prescribe prescription drugs for pain subsequent an injury which can lead to addiction [8].

\section{Pharmaceutical formulation}

Pharmaceutical formulation, in drugs, is that the procedure during which totally different chemical substances, still because of the active drug, square measure mixed to supply final medicative produce. The drugs, that are mostly used for the inducing the addiction as shown in the figure.

The word formulation is usually employed in a way that features the indefinite quantity form.

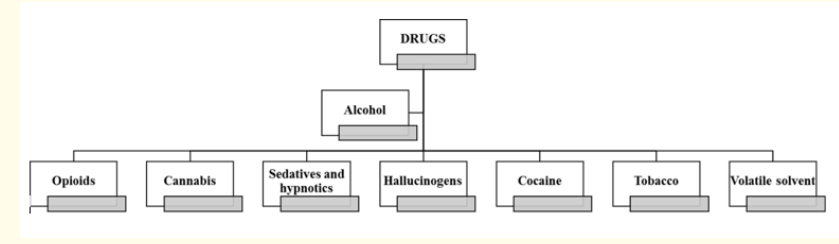

figure

\section{Examples}

Cocaine

Cocaine could be a powerfully addictive stimulant made up of the leaves of the coca plant native to South America.

Although health care suppliers will use it for valid medical functions, like anesthesia for a few surgeries, the hard drug is an associate embezzled drug.

As a drug, hard drug sounds like a fine white crystal powder. Street dealers usually combine it with things like cornflour, toilet powder, or flour to extend profits [9].

\section{Marijuana}

Marijuana refers to the dried leaves, flowers, stems, and seeds from the ganja or hemp plant. The plant contains the mind-blowing chemical drug and different similar compounds. Extracts are also created by the cannabis plant.

Marijuana is that the most ordinarily used hallucinogenic drug within u. s., when alcohol [10].

\section{Hallucinogens}

Hallucinogens area unit a various cluster of medicine that alter perception thoughts, and feelings. They cause hallucinations or sensations and pictures that appear real although they're not. Hallucinogens may be found in some plants and mushrooms (or their extracts) or maybe human-made.

People have used hallucinogens for hundreds of years, principally for spiritual rituals. Common hallucinogens embody the following: ayahuasca, DMT, D-lysergic acid diethylamide (LSD), peyote (mescaline), and 4-phosphoryloxy-N, N-dimethyltryptamine (psilocybin) [11]. 


\section{Types of tests}

A drug takes a look at could be a take a look at to seek out if you have got used a drug or medicine. They give the impression of being for terribly tiny amounts of medicine within the body.

There is a unit of differing kinds of drug tests:

Saliva tests:

- Saliva testing could be a fast, correct and reliable methodology, this manner of testing is employed in random edge drug testing.

- It is employed to notice the presence of a psychoactive substance (the active element in cannabis) and stimulant kind stimulants together with methylamphetamine ('speed' or 'ice') and methylenedioxymethamphetamine ('ecstasy'), which are, when alcohol, the medicine of greatest concern in reference to road safety.

- $\quad$ An edge spittle screening takes a look at takes around 5 minutes. Wherever a positive result's obtained, the motive force is needed to undertake the second spittle take a look at or offer a blood sample to substantiate the presence of the prescribed drug. In most cases, the collateral spittle takes a look at takes around half-hour.

\section{Blood tests}

- Blood takes a look acting is commonly used to test for recent drug use e.g. at intervals couple hours of use. This manner of testing isn't widely used because it is sort of costly.

- A sample of your blood is taken from a finger prick, or from a vein in your arm, employing a needle associated with your blood sample is going to be tested by an authorized laboratory.

\section{Urine tests}

- Urine testing is that the most typical methodology of testing because it detects drug use for an extended amount of your time (longer than blood, however not as long as hair tests) and it's easier to administer and is a lot of correct.

- Urine drug tests area unit ordinarily employed in geographical point drug testing, and typically provide correct results. If you're asked to own a piss-take a look at, you may be asked to urinate (pee) into an instrumentality and your piss are going to be tested employing a gauge.

\section{Hair tests}

- Hair testing will offer a history of drug use as traces of medicine might accumulate in your hair.

- The length of the hair will confirm however way back medicine could also be derived back. it's the sole reliable methodology that may be wont to notice drug use on the far side one or two of days or weeks.
- Most hair drug tests don't notice drug use additional back than the past three months. this manner of testing isn't widely used because it is sort of costly.

- If you're asked to own a hair drug take a look at, more or less 40-50 strands of your hair are going to be cut from the scalp line at the crown of your head and sent to a laboratory to check your hair sample for drug use.

\section{Factors affecting drug tests}

Drugs have an effect on one and all otherwise. The drug you employ (strength, dose, however usually you employ it and alternative drugs will have an effect on how long it stays in your system.

It may be laid low with you as a personal reckoning on your tolerance, age and gender, overall health, metabolism, mood and setting you're in and if you have got taken alternative medicine (including legal medicine like prescribed drugs or alcohol).

\section{Testing negative}

There is no way to mask drug use in a drug test. To test negative on a drug test, other than not taking drugs, you need to make sure your body has eliminated all of the drugs you have taken by metabolizing them

\section{Drug detection time}

The table below gives an indication* of the length of time each drug can be detected for:

\begin{tabular}{|l|c|c|c|}
\hline \multicolumn{1}{|c|}{ Drug } & Saliva Tests & Blood Tests & Urine Tests \\
\hline Amphetamines & Up to 24 hours & $4-8$ hours & $3-4$ days \\
\hline Cannabis & Up to 4 hours & 20 - 36 hours & $\begin{array}{c}18 \text { hours - } \\
90 \text { days }\end{array}$ \\
\hline Cocaine & Up to 24 hours & 40 - 90 minutes & $1-2$ days \\
\hline Ecstasy & Up to 24 hours & $4-8$ hours & $3-4$ days \\
\hline Hallucinogens & N/A & $\begin{array}{c}30 \text { minutes }-2 \\
\text { days }\end{array}$ & $1-5$ days \\
\hline Heroin & N/A & $\begin{array}{c}30 \text { mins }-3 \\
\text { hours }\end{array}$ & $1-2$ days \\
\hline Benzodiazepines & N/A & $1-100$ hours & $1-6$ weeks \\
\hline
\end{tabular}

\section{Table}

${ }^{*}$ Note: These figures are only a guide as drugs affect every person differently.

\section{Overcoming drug addiction}

Addiction to medication isn't a personality flaw or a signal of weakness, and it takes quite self-possession to beat the matter. Abusing criminal or bound prescribed drugs will produce changes within the brain, inflicting powerful cravings and a compulsion to use that produces sobriety appears to be a not possible goal. However, recovery isn't out of reach, despite however hopeless your scenario appears or what number times you've tried and unsuccessful before. With the correct treatment and support, modification is feasible. 
For many folks battling addiction, the toughest step toward recovery is that the terribly 1 st one: recognizing that you just have a haul and decided to form a modification. It's traditional to feel unsure concerning whether or not you're able to begin recovery, or if you've got what it takes to quit.

If you're captivated with a prescription, you will be concerning however you're progressing to realize an alternate thanks to treating a medical condition. It's okay to feel torn. The prescription and over-the-counter medications you are taking. It's conjointly traditional to feel conflicted concerning yield your drug of alternative, even after you recognize it's inflicting issues in your life.

Recovery needs time, motivation, and support, however by creating a commitment to vary, you'll be able to overcome your addiction and regain management of your life $[12,13]$.

\section{Think about modification}

Keep track of your drug use, as well as once and the way a lot of you utilize. This may provide you with a far better sense of the role the addiction is enjoying in your life.

List the professionals and cons of quitting, in addition, because of the prices and advantages of constant your drug use.

Consider the items that are vital to you, like your partner, your kids, your pets, your career, or your health.

Preparing for change: five key steps to addiction recovery

1. Remind yourself of the explanations you would like to vary.

2. have faith in your past makes an attempt at recovery, if any. What worked? What didn't?

3. Set specific, measurable goals, like a begin date or limits on your drug use.

4. Take away reminders of your addiction from your home, workplace, and different places you frequent

5. Tell friends and family that you're committing to recovery, and enkindle their support.

Explore your addiction treatment choices

Once you've committed to recovery, it's time to explore your treatment decisions, whereas addiction treatment will vary in line with the precise drug, a triple-crown program typically includes completely different parts, such as:

1. Detoxification: Typically, the primary step is to get rid of your body of medicine and manage withdrawal symptoms.

2. Activity direction: Individual, group, group psychotherapy will assist you to establish the foundation causes of your drug use, repair your relationships, and learn healthier brick skills.

3. Medication: Could also be wont to manage withdrawal symptoms, forestall relapse, or treat any coinciding mental state condition like depression or anxiety.
- Long-term follow-up: Will facilitate to forestall relapse and maintain sobriety. This might embody attending regular inperson support teams or on-line conferences to assist keep your recovery on target [14].

Types of drug treatment programs

- $\quad$ Residential treatment: It involves living at a facility and obtaining off from work, school, family, friends, and addiction triggers whereas undergoing intensive treatment. Residential treatment will last from many days to many months.

- Day treatment/partial hospitalization: Partial hospitalization is for people that need in progress medical observation however want to still live reception and have stable living surroundings. These treatment programs typically meet at a treatment center for seven to eight hours throughout the day, then you come home at the hours of darkness.

- $\quad$ Patient treatment: Not a live-in treatment program, these patient programs will be regular around work or college. You're treated throughout the day or evening however don't keep nightlong. The key focus is relapse interference.

\section{The keys for finding the simplest addiction treatment}

The addiction treatment of every individual is completely different depending upon their physiological structure rather than their criminal history. The distinctive scenario can be natural or tailor made. In other words, treatment ought to address quite simply your substance abuse.

Addiction affects your whole life, as well as your relationships, career, health, and psychological well-being.

Treatment success depends on developing a brand-new method of living and addressing the explanations of why you turned to medication within the 1 st place, as an example, the drug dependency might have developed from a want to manage pain or to address stress, within which case you'll get to realize a healthier thanks to relieving pain or to handle nerve-racking things.

\section{Quickly relieve stress without medication}

Different fast stress relief ways work higher for a few folks than others. The secret is to search out the one that works best for you.

\section{Movement}

A brisk walk around the block will be enough to alleviate stress. Yoga and meditation are glorious ways to bust stress and realize balance.

\section{Experiment together with the sense of smell}

Take a breath the scent of contemporary flowers or occasional beans, or savor a scent that reminds you of a favorite vacation, like cream or a shell.

\section{Build a significant sober life}

You'll be able to support your drug treatment and defend yourself from relapse by having activities and interests that offer aspir- 
ing to your life. It's vital to be concerned about things that you just fancy, that cause you to feel required, and add aspiring to your life.

Pick up a previous hobby or attempt a brand new one

Do things that challenge your power and spark your imagination-something you've invariably needed to do. Learn an instrument, a distant language, or attempt a brand new sport.

\section{Adopt a pet}

Yes, pets are a responsibility, however, caring for an animal causes you to feel idolized and required. Pets also can get you out of the house for exercise.

\section{Get entangled in your community}

Replace your addiction with sober teams and activities. Volunteer, become active in your church or religion community or be part of an area club or neighborhood cluster.

\section{Set significant goals}

Having goals to figure toward and one thing to appear forward to will be powerful antidotes to the white plague. It doesn't matter what the goals are, simply that they're vital to you.

Look after the health

Regular exercise, adequate sleep, and healthy ingestion habits assist you to keep your energy levels up and your stress levels down. The additional you'll be able to keep healthy and feel sensible, the better it'll be to remain sober.

\section{Causes relapse}

Different "triggers" will place you in danger of a relapse into previous patterns of substance use, whereas specific causes of relapse disagree from person to person, some common triggers include:

- $\quad$ Negative emotion (such as stress, sadness, anger, or trauma).

- Positive emotion (feeling happy and eager to feel even higher, like having an honest time with friends).

- Physical discomfort (such as pain or withdrawal symptoms).

- Trying to check your personal management ("I will use simply once" or "have only 1 pill").

- Social pressure (being in a very scenario wherever it appears everybody else is using) $[15,16]$.

\section{Conclusion}

Drug addiction may be an advanced malady that results from a variety of things like genetic predisposition, history of violence reception and stress. Researchers are able to determine the factors that result in abuse. Understanding the foundation reason behind dependence is one in all the simplest ways to enhance treatment choices and outcomes of dependence in the future. A lot of people do not understand why people get addicted to drugs and related substances. They erroneously read abuse as a social drawback and characterize the addict as a weak person. There's no scientific proof on however specifically medication adds brain, it will be with success treated to assist individuals to stop abusing the medication. There are a unit several treatments that facilitate individuals counteract the unquiet effects of dependence and regain complete management over life. Behavioral medical aid is that the best thanks to guaranteeing success in most of the drug addicts. The treatment approaches area unit tailored to satisfy the abuse pattern of patients. It's not uncommon for a person to relapse and begin abuse once more. In such a case, associate degree alternate treatment is needed to regain management and recover fully.

\section{Bibliography}

1. Introduction. Essay on Drug Addiction in Youth (2020).

2. Introduction (2020).

3. Introduction. Drug addiction (2020)

4. Chang BS and Hershenson S. "Practical approaches to protein formulation development". In "Rationale Design of stable protein formulations-theory and practice" (JF Carpenter and MC Manning eds.) Kluwer Academic/Plenum publishers, New York (2002): 125.

5. M Nocent., et al. "Definition of a solvent system for spherical crystallization of salbutamol sulfate by quasi-emulsion solvent diffusion (QESD) method". Journal of Pharmaceutical Sciences 90.10 (2001): 1620-1627.

6. Reason. 10 Reasons Why People Abuse Drugs (2020).

7. The 10 Hardest Drugs to Kick.

8. Which drugs are the most addictive? (2020)

9. Formulation. What is cocaine? (2020).

10. Formulation. Marijuana (2020).

11. Formulation. Hallucinogens (2020).

12. Simler R., et al. "Maximizing Data Collection and Analysis During Preformulation of Biotherapeutic Proteins". BioProcess International 6.10 (2008): 38-45.

13. Carpenter., et al. "Rationale Design of Stable Lyophilized Protein Formulations: Some Practical Advice". Pharmaceutical Research 14.8 (1977): 969-975.

14. Treatment. Understanding Drug Use and Addiction (2020).

15. Treatment. Drug addiction (substance use disorder) (2020).

16. David Nutt., et al. "Development of a Rational Scale to Assess the Harm of Drugs of Potential Misuse". Lancet 369.9566 (2007): 1047-1053. 
Assets from publication with us

- Prompt Acknowledgement after receiving the article

- Thorough Double blinded peer review

- Rapid Publication

- Issue of Publication Certificate

- High visibility of your Published work

Website: $\underline{w w w . a c t a s c i e n t i f i c . c o m / ~}$

Submit Article: www.actascientific.com/submission.php

Email us: editor@actascientific.com

Contact uS: +919182824667 